\title{
Heavy Metal Poisoning in a Cockatiel (Nymphicus hollandicus)
}

\author{
Estéfanni de Castro Pinheiro', Rafael César de Melo², André Grespan², Tainara Micaele Bezerra Peixoto, \\ Maressa Holanda dos Santos ${ }^{3}$, Leonardo Alves Rodrigues Cabral ${ }^{3} \&$ Paula Priscila Correia Costa ${ }^{4}$
}

\begin{abstract}
Background: In recent decades the demand for unconventional pets has been relatively increasing, a situation that increasingly causes veterinarians to encounter these animals in medical and surgical practice. Of these animals, the birds stand out. Animals of the order Psittaciform are known as very curious and active creatures that have the tendency to chew objects in their environment. Among the several occurrences that lead this animal to attend the veterinary clinic, we highlight the poisoning by heavy metals, especially lead poisoning $(\mathrm{Pb})$ and zinc $(\mathrm{Zn})$. The objective of this work was to report a case of heavy metal intoxication in cockatiel (Nymphicus hollandicus).

Case: A cockatiel was taken to the veterinarian with a history of apathy, motor incoordination, exacerbated water consumption and regurgitation. Complete anamnesis was instrumental in directing suspected heavy metal intoxication. Radiopaque particles were visualized through radiographic examination, suggesting heavy metal intoxication. The diagnosis was concluded through complementary examinations since the clinical symptoms are nonspecific. The treatment was intended to provide emergency intervention, avoid further absorption, use of antidotes, provide supportive measures and provide guidance to the owner. It can be concluded that the diagnosis and treatment were successful.

Discussion: Metal poisoning can kill birds. The veterinarian should always seek the literature in order to perform the best support and treatment. For this, detailed history and detailed medical history must be taken into account, since the time of ingestion and the type of metal interfere with the therapeutic conduct. The use of imaging tests such as X-rays and ultrasound are essential to assist the clinician, especially in cases where the tutor does not know whether or not the animal has ingested an object. In the radiographic examination, the heavy metal has the characteristic of having high radiopacity, which was evidenced in the case in question. Radiographic positions should be considered in order to avoid false negatives. In the literature, the treatment of chelation therapy is prioritized to remove the circulating heavy metal and thus act on the cause of the problem. In the case in question calcium EDTA was used intramuscularly, which showed clinical improvement in the animal after the second application. Calcium EDTA binds to metals and facilitates their transport and excretion. The use of fluid therapy is necessary as a supportive treatment to prevent kidney damage, since heavy metals are highly harmful to nephrons. Especially in cases where the animal stops feeding and ingesting water. The use of antibiotics is essential because in many cases the animal, in addition to not feeding, becomes prone to infections due to metal toxicity, therefore, prophylactic use is essential for a better prognosis. In the case in question, the use of enrofloxacin was effective, as reported in the literature. It is recommended that the diagnosis of serum lead and zinc dosage should be made, however, due to the difficulties of obtaining the samples, and since other metals may also cause intoxication, in the case in question the treatment was started without these results. According to the results obtained in this work, the treatment described in the literature is effective and can be performed immediately to save animal life without subsequent sequelae.
\end{abstract}

Keywords: bird, lead, zinc, calcium EDTA. 


\section{INTRODUCTION}

The growth of wild animals as pets requires the Veterinary Medicine professional to increase their knowledge on non-conventional pet species [4]. The cockatiels (Nymphicus hollandicus) are exotic birds of Australian origin, belonging to the order Psittaciforme, family Psittacidae [24]. Animals of the order Psittaciform are known as very curious and active creatures that have the tendency to chew objects in their environment [1]. Among the several occurrences that lead this animal to attend the veterinary clinic, we highlight the poisoning by heavy metals. Being poisoning by lead $(\mathrm{Pb})$ and zinc $(\mathrm{Zn})$ are the most common causes of heavy metal toxicity in pet birds, zoological and aquatic collections $[1,7]$. The clinical signs of lead and zinc poisoning are regurgitation, diarrhea, polydipsia and polyuria, anorexia, dyspnea, depression, weakness, ataxia, seizures, weight loss, and may lead to death. [7,18]. The diagnosis should be based on a combination of clinical history, physical examination and complementary exams, such as radiographs, that allow the visualization of metallic objects in the gastrointestinal tract. Treatment includes supportive therapy and the use of specific chelating agents. The objective of this work was to report a case of heavy metal intoxication in a cockatiel (Nymphicus hollandicus).

\section{CASE}

A cockatiel was treated at a veterinary clinic with approximately three years of age and a history of apathy, motor incoordination, exacerbated water consumption and regurgitation. In the anamnesis it was reported that the animal was kept in a cage that was in the external environment of the house during the day, and the night inside the house. There were no contacts. The cage hung from the wall and had no heating source. It was reported that the bird pecked the wall. She was fed daily with industrialized pelleted ration proper to the species and varied fruits on alternate days.

At the physical examination, the body score of the bird that was regular, weighing $79 \mathrm{~g}$ and the clinical signs were checked. The veterinarian requested immediate hospitalization of the cockatiel in order to stabilize the clinical picture and perform complementary tests (radiographic, hemogram and biochemical examination). During hospitalization, treatment consisted of Enrofloxacin suspension (Enrologic Monami $\left.{ }^{\circledR}\right)^{1}$ [5 mg.kg-1 PO q12 h during 7 days], Dipyrone syrup (Dipirona $\left.{ }^{\circledR}\right)^{2}$ [1 mg.kg-1 PO q12 h during 5 days], fluid therapy with saline solution $0.9 \%$ (Cloreto de Sódio $0,9 \%()^{3}$ heated and vitaminized $2 \mathrm{~mL}$ glucose (Solução de Glicose $5 \%()^{4}$ during 1 day.

Radiographic examination was performed two days after admission. The bird was radiographed at the laterolateral and ventrodorsal positions on the digital $\mathrm{X}$-ray apparatus set at $68 \mathrm{Kv}$ and exposure time of 0.04 s. The method of containment used was the manual. A new radiographic examination was performed after a period of 10 days.

Blood samples were collected in a $0.5 \mathrm{~mL}$ tube, by puncture of the left ulnar vein, and the animal was under inhalation anesthesia with isoflurane for hemogram and uric acid dosing.

After the results of the tests, the animal remained hospitalized without medical discharge, continuing the treatment already started. Calcium EDTA ${ }^{5}$ chelating therapy was initiated at a dose [40 mg.kg-1 IM q12 h during 5 days]. In the fluid therapy, a solution of $0.9 \%$ saline $^{3}$ and vitaminized glucose $\mathrm{e}^{4}$, with a content of $1 \mathrm{~mL}$, was used and was performed once daily subcutaneously for another five days.

The cockatiel was kept in an enclosure and individual, in an environment with ceramic lamp for heating. During the first three days of treatment, the feed was forced through a metal probe twice daily containing 3-5 mL of potato solution for psittacines with filtered, heated water. After two weeks and two days under veterinary care, the animal was discharged.

\section{DISCUSSION}

Heavy metal poisoning is the most common toxicose reported in birds [20]. Reports of this intoxication in captive birds are becoming frequent, especially in parrots who are extremely curious and tend to ingest foreign materials. Being lead $(\mathrm{Pb})$ and zinc $(\mathrm{Zn})$ are the most common metals [7].

The history reported by the owner is important to guide the veterinarian to the presumptive diagnosis. Thus, the clinical picture should be the basis for a presumptive diagnosis, excluding infectious-contagious and metabolic diseases [13].

Regarding symptomatology, the bird presented apathy, motor incoordination, exacerbated water consumption, moderate degree of dehydration, regurgitation, bruised feathers and diarrhea. Although non-specific, such signs are described in the literature as frequent in cases of heavy metal poisoning and may evolve to death. $[1,3,6,25]$. 
The cockatiel did not present convulsions, which are common symptoms of heavy metal poisoning, being more frequent by lead [3,21]. Apathy and diarrhea may occur in lead and zinc poisoning.

Radiographic examination revealed the presence of radiopaque particles located in the proventriculus and ventricle regions, suggestive of heavy metals (Figure 1). After a 10-day period of medical discharge, a new radiographic examination was performed, and radiopaque particles (with heavy metal density) were not present (Figure 2). Although the investigation of plasma concentration of zinc and lead was not performed, this examination was fundamental to establish the diagnosis, since it was possible to visualize radiopaque particles.

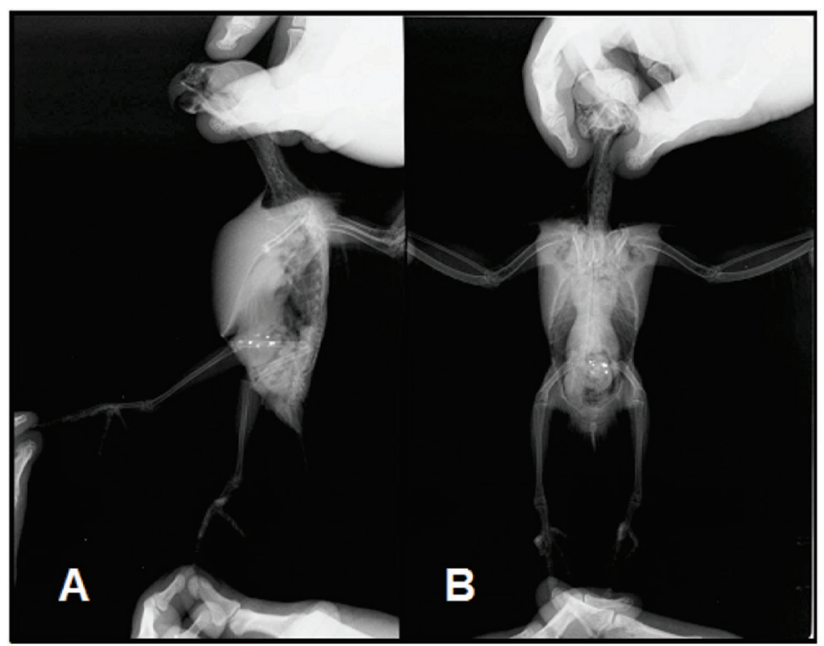

Figure 1. A- Radiographs of the lateral-lateral projection. B- Ventrodorsal projection. Two days after hospitalization showing the presence of radiopaque material suggestive of heavy metal (red arrow).

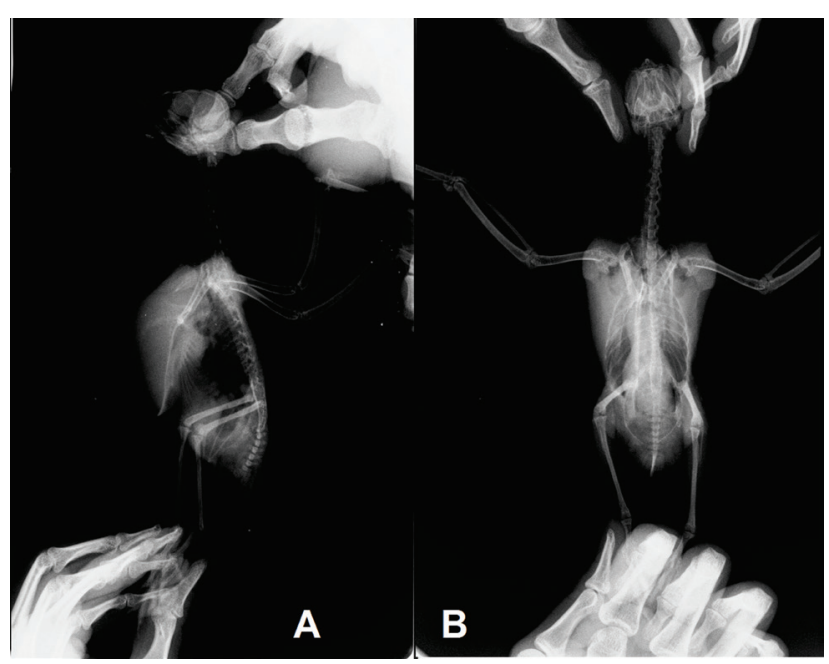

Figure 2. A- Radiographs of the lateral-lateral projection. B- Ventro-dorsal projection. After a 10-day medical discharge period. Note the absence of radiopaque material previously observed.
Radiographs are useful because they revealed metal particles with high radiopacity, different from mineral particles that are less radiopaque. Radiography is the most commonly used imaging test because it is simple, non-invasive, and has a relatively low cost $[8,14]$. The two projections performed in the case, latero-lateral and ventro-dorsal, are recommended. [11]. Radiographs were taken after two days with the stabilization of the clinical picture of the animal, and after 10 days of medical discharge, where it was possible to verify the absence of radiopaque particles as recommended [8].

Heavy metal poisoning in poultry often occurs by ingestion of substances containing lead, or possibly zinc [6]. In this case, the ingestion of wall paint by a cockatiel (Nymphicus hollandicus) was reported. The wall paint is one of the materials that have heavy metal in its composition, as well as metal parts of cages and nurseries, weights, bells with bells lead batteries, lead pellets, jewelry, stained glass, including contaminated drinking water, among others $[3,8,17]$.

For the definitive diagnosis it is necessary the dosage of the serum levels of zinc and lead or the analysis of the foreign body $[13,15,18]$. Dosage efficacy is challenged as poultry may show clinical signs without the presence of high concentrations. In addition, often in small poultry, such as cockatiel, it is impossible to perform the examination because of the amount of sample required by the laboratory. These analyzes require specific equipment and laborious procedures [19]. There are few laboratories in Brazil that do this exam, the cost and delay of the report makes it difficult. In addition, other metals also cause intoxication and disease; Therefore, the absence of lead and zinc in a suspected sample does not completely exclude the poisoning of a patient by heavy metal [12].

In the present study, it was not necessary to carry out research on the toxic agent to establish the treatment protocol. It is indicated to initiate chelation therapy before receiving the results of heavy metal dosing in critically ill birds. [22].

The various treatment reports that may be used prioritize the use of chelation therapy. In this case, the chelator Calcium EDTA was used intramuscularly, which is the chelating agent of initial choice $[2,3,6,13,14,16]$. The dose used is as described in the literature [5]. 
Calcium EDTA has the ability to form a complex with metals, which increases its mobilization and excretion [9]. The weakly bound extracellular lead is excreted rapidly [17]. After two applications of calcium EDTA, the animal showed improvement of clinical symptoms, returning to feed itself. Significant improvement in bird condition after initiation of therapy with Calcium EDTA suggests that radiopaque particles represented heavy metals [18].

Supporting treatment with fluid therapy was necessary, and this procedure is recommended in an attempt to prevent nephrotoxicity due to the use of chelating agents in birds.

Enrofloxacin, a broad-spectrum antibacterial agent of the fluoroquinolone class, has been used because of the major immunotoxic effect observed in individuals exposed to lead: increased susceptibility to infectious processes of bacterial origin, with a deficiency in immune, humoral and cellular responses [9,11]. With the improvement of the picture, the animal was discharged and returned home, returning only for review 10 days after this.

This case demonstrates the validity of initiating chelation therapy based on clinical and radiographic findings and the rapid response that is obtained if the diagnosis is correct.

From the first service, the owner was advised on where the bird was, to avoid contact with wall paint, and on the tendency of these birds to play with metallic objects, to avoid future problems of heavy metal intoxication. The recommendations made to the owner were pertinent, since the intoxication tables are directly related to the management, and, in the case of birds kept in captive domicile, are the responsibility of the owner.

The medical clinic in birds is a promising specialty because of the considerable increase of these animals as pets. Whereas metal intoxication still leads to death of some animals the veterinarian should seek knowledge about this toxicology. In addition, owners should be advised in order to provide the welfare of these animals as heavy metal poisoning can be avoided with handling care.

It can be concluded, according to the results obtained in this work, that the treatment described in the literature is effective and can be performed immediately to save animal life without later sequelae.

\section{MANUFACTURERS}

${ }^{1}$ Mon Ami Pharmalogic Animal Health. São José dos Campos, SP, Brazil.

${ }^{2}$ Laboratório Biovet. Vargem Grande Paulista, SP, Brazil. ${ }^{3}$ Fresenius Kabi Brasil Ltda. Aquiraz, CE, Brazil. ${ }^{4}$ JP Indústria Farmacêutica S/A. Ribeirão Preto, SP, Brazil. ${ }^{5}$ Biodinâmica Química e Farmaceutica. Ibiporã, PR, Brazil.

Declaration of interest. The authors report no conflicts of interest. The authors alone are responsible for the content and writing of the paper.

\section{REFERENCES}

1 Aizenberg I., Miara L. \& Ulman O. 2006. Heavy metal toxicity in psittacine birds. Israel Journal of Veterinary Medicine. 61: 28-29.

2 Beyer W.N., Dalgarn J., Dudding S., French J.B., Mateo R., Miesner J., Sileo L. \& Spann J. 2004. Zinc and lead poisoning in wild birds in the Tri-State Mining District (Oklahoma, Kansas, and Missouri). Archives of Environmental Contamination and Toxicology. 48: 108-117.

3 Bowles H., Litchenberguer M. \& Lennox A. 2007. Emergency and Critical Care of Pet Birds. Veterinary Clinics of North America - Exotic Animal Practice. 10: 345-349.

4 Carniatto C.H.O. \& Leonardo J.M.L.O. 2014. Aves silvestres atendidas no Hospital Veterinário do Centro Universitário de Maringá - Cesumar. Revista em Agronegócios e Meio Ambiente. 7: 227-238.

5 Carpenter J.W. 2010. Birds. In: Christopher J.M. (Ed). Exotic Animal Formulary. 3rd edn. v.2. St. Louis: Elsevier Saunders, 576p.

6 Chow C. \& Pollock C. 2009. Heavy Metal Poisoning in Birds. Fonte:<https://lafeber.com/vet/heavy-metal-poisoningin-birds/> [Accessed online in May 2015].

7 Delk K. 2012. Clinical Management of Seizures in Avian Patients. Journal of Exotic Pet Medicine. 21: 132-139.

8 Francisco N., Troya J.D.R. \& Aguera E.I. 2003. Lead and lead toxicity in domestic and free living birds. Avian Pathology. 32: 3-13.

9 Godoy S.N. 2007. Psittaciformes. In: Cubas Z.S., Silva J.C.R. \& Catão-Dias J.L. (Eds). Tratado de animais selvagens. São Paulo: Roca, 248p. 
10 Harcourt-Brown N.H. 2010. Psitaciform Birds. In: Tully T.N., Dorrestein G.M. \& Jones A.K. (Eds). Handbook of Avian medicine. 2nd edn. Philadelphia: Saunders, pp.122-149.

11 Harris D.J. 2009. Clinical tests. In: Tully T.N., Dorrestein G.M. \& Jones A.K. (Eds). Handbook of Avian medicine. 2nd edn. Philadelphia: Saunders, pp.43-51.

12 Labonde J. 1995. Toxicity in pet avian patients. Seminars in Avian and Exotic Pet Medicine. 4(1): 23-31.

13 Langlois I. 2003. The anatomy, physiology, and diseases of the avian proventriculus and ventriculus. Veterinary Clinics of North America - Exotic Animal Practice. 6: 85-111.

14 Lawrie A. 2005. Systemic non-infectious disease ingested toxins. In: Harcourt-Brown N. \& Chitty J. (Eds). Manual of pittacine birds. 2nd edn. Gloucester: British Small Animal Veterinary Association, pp.254-255.

15Lightfoot T.L. \& Yeager J.M. 2008. Pet Bird Toxicity and Related Environmental Concerns. Veterinary Clinics of North America - Exotic Animal Practice. 11: 229-259.

16 Madani S.A., Vajihi A., Rostami A., Mohamad M.D., Soroori S. \& Khazaeli F.A. 2007. Clinical and Radiographic Findings of Heavy Metal Poisoning in Psittacine Birds. Iranian Journal of Veterinary Surgery. 2(5): 17-21.

17 Mcdonald S.E. 1986. Lead poisoning in psittacine birds. In: Kirk R.B. (Ed). Current veterinary therapy small animal practice. 9th edn. Philadelphia: Saunders, pp.713-718.

18 Murase T., Horiba N., Goto I., Yamato O., Ikeda T. \& Sato K. 1993. Erythrocyte ALA-d activity in experimentally lead-poisoned ducks and its change during treatment with disodium calcium EDTA. Research in Veterinary Science. 55: 252-257.

19 Peterson M.E. \& Talcott P.A. 2012. Zinc. In: Winkel A.J. \& Stringer S. (Eds). Small Animal Toxicology. 3rd edn. Philadelphia: Elsevier, pp.265-268.

20 Pollock C. 2006. Diagnosis and Treatment of Avian Renal Disease. Veterinary Clinics of North America - Exotic Animal Practice. 9: 107-128.

21 Quesenberry K.E. \& Hillyer E.V. 1994. Supportive care and emergency therapy. In: Ritchie B.W., Harrison G.J. \& Harrison L.R. (Eds). Avian medicine: principles and application. Lake Worth: Wingers, pp.382-416.

22 Stanford M. 2005. Calcium metabolism. In: Harrison G.J. \& Lightfoot T.L. (Eds). Clinical avian medicine. Palm Beach: Spix, pp.1-23.

23 Woods L.W. \& Plumlee K.H. 1999. Avian Toxicoses: Veterinary Diagnostic Laboratory Perspective. Seminary in Avian and Exotic Pet Medicine. 8(1): 32-35. 